OPEN ACCESS

Edited by:

Gengtao Fu,

Nanyang Technological

University, Singapore

Reviewed by:

Shuai Wang,

Qilu University of Technology, China

Lin LV,

Central China Normal University, China

*Correspondence:

Haitao Wang

wanghaitao@wit.edu.cn

Hongfang Liu

liuhf@hust.edu.cn

Specialty section:

This article was submitted to Green and Sustainable Chemistry,

a section of the journal

Frontiers in Chemistry

Received: 12 October 2019 Accepted: 25 November 2019 Published: 12 December 2019

Citation:

Wang H, Qiu X, Wang W, Jiang $L$ and Liu H (2019) Iron Sulfide Nanoparticles Embedded Into a Nitrogen and Sulfur Co-doped Carbon Sphere as a Highly

Active Oxygen Reduction

Electrocatalyst. Front. Chem. 7:855

doi: 10.3389/fchem.2019.00855

\section{Iron Sulfide Nanoparticles Embedded Into a Nitrogen and Sulfur Co-doped Carbon Sphere as a Highly Active Oxygen Reduction Electrocatalyst}

\author{
Haitao Wang ${ }^{1 *}$, Xiaoyu Qiu ${ }^{2}$, Wei Wang ${ }^{3}$, Lipei Jiang ${ }^{2}$ and Hongfang Liu ${ }^{2 *}$ \\ ${ }^{1}$ Key Laboratory for Green Chemical Process (Ministry of Education), School of Chemistry and Environmental Engineering, \\ Wuhan Institute of Technology, Wuhan, China, ${ }^{2}$ Key Laboratory of Material Chemistry for Energy Conversion and Storage \\ (Ministry of Education), School of Chemistry and Chemical Engineering, Huazhong University of Science and Technology, \\ Wuhan, China, ${ }^{3}$ School of Chemistry and Chemical Engineering, Hunan Institute of Science and Technology, Yueyang, China
}

The unique micro/mesoporous spherical nanostructure composed of non-noble metal nanoparticles encapsulated within a heteroatom-doped carbon matrix provides great advantages for constructing advanced non-precious oxygen reduction (ORR) electrocatalysts. Herein, a promising oxygen electrocatalyst comprising iron sulfide $\left(\mathrm{Fe}_{1-x} \mathrm{~S}\right)$ nanoparticles embedded into a nitrogen and sulfur co-doped carbon sphere ( $\left.\mathrm{Fe}_{1-\mathrm{x}} \mathrm{S} / \mathrm{NS}-\mathrm{CS}\right)$ is successfully explored through a simple and fast polymerization between methylolmelamines (MMA) and ammonium ferric citrate (AFC) as well as a high-temperature vulcanization process. Moreover, the proposed polymerization reaction can be finished completely within a very short time, which is useful for large-scale manufacturing. Impressively, the developed $\mathrm{Fe}_{1_{-x}} \mathrm{~S} / \mathrm{NS}-\mathrm{MCS}$ catalyst demonstrates outstanding ORR catalytic activity in terms of a more positive onset and half-wave potential as well, as much a better methanol tolerance and stability, in comparison with that of $\mathrm{Pt} / \mathrm{C}$ benchmarked catalyst. The remarkable ORR electrocatalytic properties are strongly associated with the favorable characteristic spherical $\mathrm{N}$, the $\mathrm{S}$ co-doped porous graphitic carbon nanoskeleton incorporated with the $\mathrm{Fe}_{1-x} \mathrm{~S}$ nanoparticle-encapsulation structure.

Keywords: facile synthesis strategy, iron sulfide nanoparticles, carbon spheres, nitrogen and sulfur dual-doping, oxygen reduction

\section{INTRODUCTION}

The oxygen reduction reaction (ORR) is of great importance to cathode reactions in a class of various renewable electricity techniques, including metal-air batteries and proton exchange membrane fuel cells (Liu et al., 2019; Zhang et al., 2019). However, the thermodynamic barrier and sluggish kinetics of ORRs have always hindered the development of these technologies (Guo et al., 2019; Wang et al., 2019b). Therefore, a low-cost and high-efficiency ORR electrocatalyst is the key to the large-scale commercialization of such sustainable green energy technologies (Wang S. et al., 2018; Wang et al., 2019a; Yuan et al., 2019). Until now, noble metals-based ORR electrocatalysts have generally been considered to be the best choice to expedite the ORR process, but the rocketing costs, scarce resources, and poor durability inhibit their more widespread applications 
(Greeley et al., 2009; Dai et al., 2015). The development of cost-effective alternatives to precious metals as efficient ORR catalysts, therefore, is of great importance; but this development faces several great challenges. Recently, tremendous efforts have demonstrated that the coordination of iron species with $\mathrm{N}$-doped carbon frameworks $(\mathrm{Fe} / \mathrm{N}-\mathrm{C})$ possess better ORR catalytic activity than simple N-doped carbon matrices. The promising electrocatalytic activity can be ascribed to the synergistic effect between Fe species and the surface nitrogen and carbon (Chen Z. et al., 2011; Jaouen et al., 2011; Kim et al., 2013). In this respect, various Fe compounds, such as oxides, carbides, and nitrides, have been explored as ORR catalysts, including $\mathrm{Fe}_{3} \mathrm{O}_{4} / \mathrm{N}$-doped mesoporous carbon spheres (Wang et al., 2017b), $\mathrm{Fe}_{3} \mathrm{C} / \mathrm{N}$-doped carbon nanosheets, and $\mathrm{Fe}_{2} \mathrm{~N} @ \mathrm{~N}$-doped mesoporous graphitic carbon (Xiao et al., 2016; Wang H. et al., 2018). Although, some progress has been made in the study of $\mathrm{Fe} / \mathrm{N}-\mathrm{C}$ catalysts in the past decade, the ORR catalytic performance is still inferior to noble metals-based electrocatalysts.

Fortunately, recent studies have shown that the ORR electrocatalytic properties of $\mathrm{Fe} / \mathrm{N}-\mathrm{C}$ materials can be improved by introducing sulfur into Fe/N-C (Wang et al., 2015), since the electron spin effect results in the change of charge distribution for the carbon framework (Jeon et al., 2013; Wu et al., 2016), thereby improving the electrical conductivity. In addition, the introduction of $\mathrm{S}$ species can also combine with transition metals to form a new type of iron sulfide active site, thus further enhancing the ORR catalytic performance (Xiao et al., 2017a,b). For instance, Jin et al. (2018) synthesized the Fe/N/S-CNTs via pyrolysis of hydrazine hydrate and ferrous sulfate-treated ZIF-8. Xiao et al. (2017a) fabricated the $\mathrm{Fe}_{1-\mathrm{x}} \mathrm{S} / \mathrm{N}, \mathrm{S}-\mathrm{MGCS}$ catalyst via a two-step pyrolysis and acid-leaching process. However, the above synthetic method is not only tedious and timeconsuming, but also involves the use of expensive and dangerous chemicals. Therefore, exploring an environmentally friendly and facile approach to fabricate the S-coordinated $\mathrm{Fe} / \mathrm{N}-\mathrm{C}$ composites is consequently significant, but it remains challenging.

Being mindful of the above ideas, this paper proposes a facile and fast strategy to fabricate iron sulfide $\left(\mathrm{Fe}_{1-\mathrm{x}} \mathrm{S}\right)$ nanoparticles embedded into a nitrogen and sulfur co-doped carbon sphere $\left(\mathrm{Fe}_{1-\mathrm{x}} \mathrm{S} / \mathrm{NS}-\mathrm{CS}\right)$ through a simple and quick polymerization between methylolmelamines (MMA) and ammonium ferric citrate (AFC), as well as the subsequently high-temperature vulcanization process. Importantly, the proposed polymerization reaction can be finished completely within a very short time $(7 \mathrm{~min})$, which makes it useful for large-scale manufacturing. Moreover, together with the advantages of the characteristically spherical $\mathrm{N}, \mathrm{S}$ codoped a porous graphitic carbon nanoskeleton incorporated with the $\mathrm{Fe}_{1-\mathrm{x}} \mathrm{S}$ nanoparticle-encapsulation structure; the resulting $\mathrm{Fe}_{1-\mathrm{x}} \mathrm{S} / \mathrm{NS}-\mathrm{CS}$ demonstrated an outstanding ORR catalytic activity in terms of a more positive onset and half-wave potential, as well as much better methanol tolerance and stability, in comparison with that of the $\mathrm{Pt} / \mathrm{C}$ benchmarked catalyst.

\section{EXPERIMENTAL SECTION}

\section{Synthesis of $\mathrm{Fe}_{1-\mathrm{x}} \mathrm{S} / \mathrm{NS}-\mathrm{CS}$}

Typically, $2.81 \mathrm{~g}$ of melamine is added into $5.6 \mathrm{~mL}$ of formaldehyde with constant stirring until it forms a homogeneous transparent solution at $65^{\circ} \mathrm{C}$. Meanwhile, $0.04 \mathrm{~g}$ of AFC and $0.56 \mathrm{~g}$ of poly (vinyl alcohol) are dissolved completely in $80 \mathrm{~mL}$ of deionized water to form a uniform orange liquid. Then the two solutions are stirred at $60^{\circ} \mathrm{C}$ to mix homogeneously. Subsequently, $1.3 \mathrm{~mL}$ of acetic acid is injected into the above mixed liquid with continuous stirring at $60^{\circ} \mathrm{C}$ for $7 \mathrm{~min}$ to produce the Fe containing nitrogen-rich carbon polymer spheres (Fe-NCPS). Next, $0.35 \mathrm{~g}$ of Fe-NCPS sample is annealed at $600^{\circ} \mathrm{C}$ under $\mathrm{N}_{2}$ protection with a ramp rate of $1^{\circ} \mathrm{C} \mathrm{min}^{-1}$ for $1 \mathrm{~h}$ to form Fe-containing $\mathrm{N}$-doped carbon spheres (Fe/N-CS). Finally, $0.06 \mathrm{~g}$ of the Fe/N-CS sample and $10 \mathrm{~g}$ of thiourea are placed in the center and front end of tube furnace, respectively, and they are then heated to $850^{\circ} \mathrm{C}$ for $1 \mathrm{~h}$ with a heating rate of $10^{\circ} \mathrm{C} \mathrm{min}^{-1}$ and an argon flow of $100 \mathrm{sccm}$. After that, the $\mathrm{Fe}_{1-\mathrm{x}} \mathrm{S} / \mathrm{NS}-\mathrm{CS}$ catalyst is obtained.

\section{Synthesis of NS-CS, $\mathrm{Fe}_{3} \mathrm{O}_{4} / \mathrm{NS}-\mathrm{CS}$ and $\mathrm{N}-\mathrm{CS}$}

For comparison, the NS-CS control sample is prepared in a similar way without the addition of AFC. Moreover, the $\mathrm{Fe}_{3} \mathrm{O}_{4} / \mathrm{N}$-CS control material is also synthesized by a similar way, just replacing thiourea with urea in the process of synthesis. Additionally, the N-CS control catalyst is obtained through a similar way without adding AFC and replacing thiourea with urea.

\section{RESULTS AND DISCUSSION}

The $\mathrm{Fe}_{1-\mathrm{x}} \mathrm{S} / \mathrm{NS}$-CS catalyst was fabricated via a facile threestep method, including polyreaction, pyrolysis, and a hightemperature vulcanization step, as schematically displayed in Figure 1 (Experimental detail, Supplementary Material). Firstly, a simple hydroxymethylation happened between the formaldehyde (FA) and melamine (MA) molecules, which resulted in the formation of MMA (Ma et al., 2012). Then, the formed MMA species were polymerized with AFC (Wang et al., 2017b) under the catalysis of acetic acid and with the existence of poly (vinyl alcohol) (PVA), ultimately resulting in the Fe-containing nitrogen-rich carbon polymer spheres (Fe-NCPS). It is worth mentioning that the polymerization reaction was finished completely within a very short time ( $7 \mathrm{~min})$. Thus, the method outlined here is simple and quick to operate, and this makes it useful for large-scale manufacturing. Next, the Fe-NCPS samples were annealed at $600^{\circ} \mathrm{C}$ under $\mathrm{N}_{2}$ protection to form Fe-containing $\mathrm{N}$ doped carbon spheres (Fe/N-CS). Finally, the obtained Fe/NCS samples were vulcanized into iron sulfide/nitrogen and a sulfur co-doped carbon sphere $\left(\mathrm{Fe}_{1-\mathrm{x}} \mathrm{S} / \mathrm{NS}-\mathrm{CS}\right)$ by the pyrolysis of thiourea.

Figure 2 displays the morphologies and microstructures of $\mathrm{Fe}$ NCPS and $\mathrm{Fe}_{1-\mathrm{x}} \mathrm{S} / \mathrm{NS}-\mathrm{CS}$. It can be seen from Figures $\mathbf{2 a} \mathbf{a} \mathbf{b}$ that 

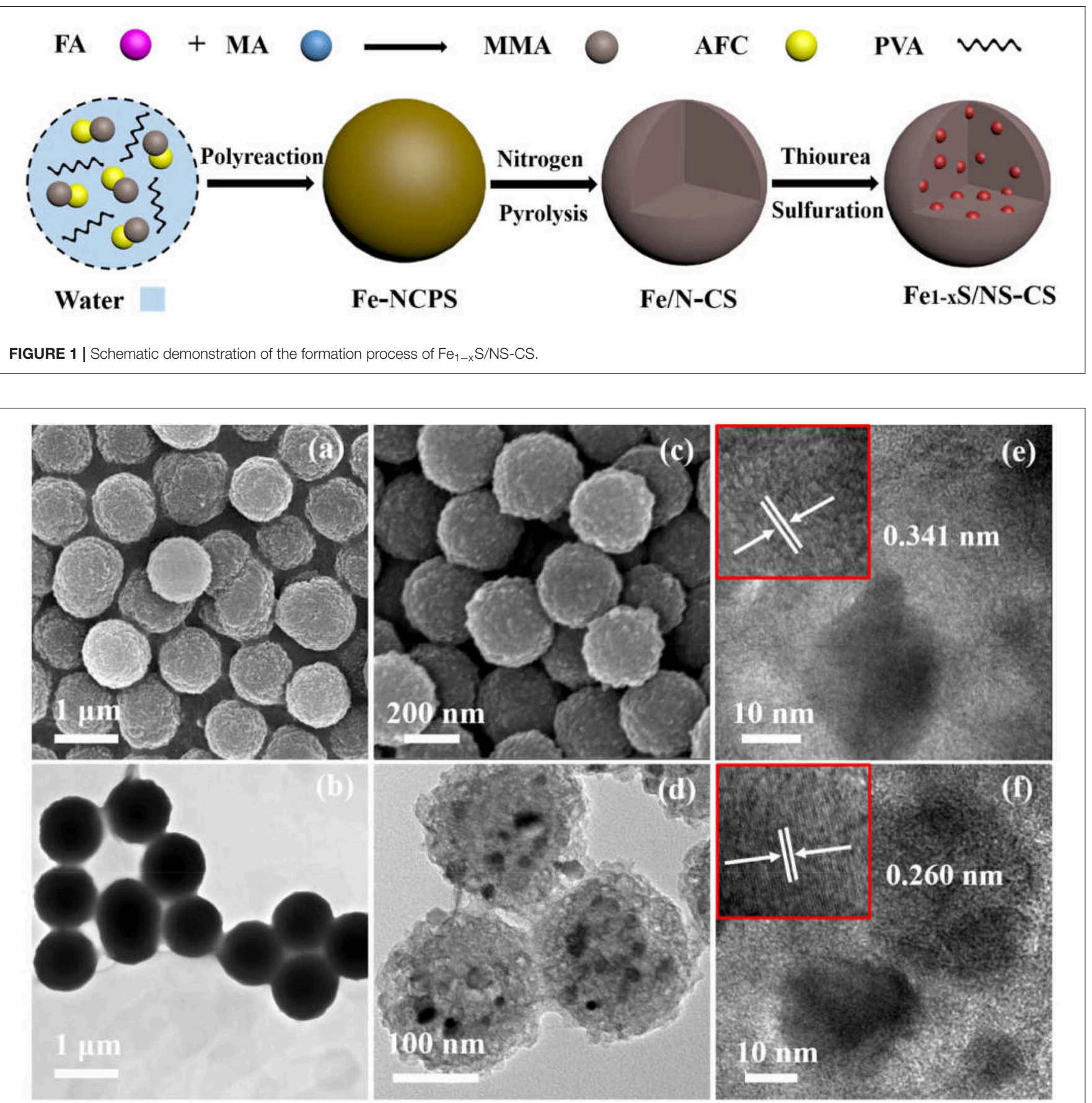

FIGURE 2 | (a) SEM image and (b) the corresponding TEM image of Fe-NCPS. (c) SEM image and (d) the corresponding TEM image of Fe 1-x $_{1}$ /NS-CS. (e,f) HRTEM images of $\mathrm{Fe}_{1-x} \mathrm{~S} / \mathrm{NS}-\mathrm{CS}$.

the Fe-NCPS have well-defined, solid, spherical morphologies with diameters of $\sim 800 \mathrm{~nm}$. After the pyrolysis process and high-temperature vulcanization step, the similar spherical morphologies are also retained (Figures 2c, 3D). However, the diameter of the carbon spheres obviously decrease from 800 to $\sim 200 \mathrm{~nm}$. Moreover, fair amounts of nanoparticles, indicated by black dots, are seen to be embedded in the spherical carbon skeleton. The XRD result in Figure 3A indicates that the nanoparticles are assigned to the crystalline $\mathrm{Fe}_{1-\mathrm{x}} \mathrm{S}$ (JCPDS: 22-1120). In Figure 3A, the peaks located at about 29.9, 33.9, 43.8 , and $53.2^{\circ}$ are attributed to the crystal planes of (200), (204), (208), and (220) of crystalline $\mathrm{Fe}_{1-\mathrm{x}} \mathrm{S}$ (JCPDS: 22$1120)$, respectively. The result suggests that the iron species in Fe-NCPS samples are transformed into $\mathrm{Fe}_{1-\mathrm{x}} \mathrm{S}$ after the 
A
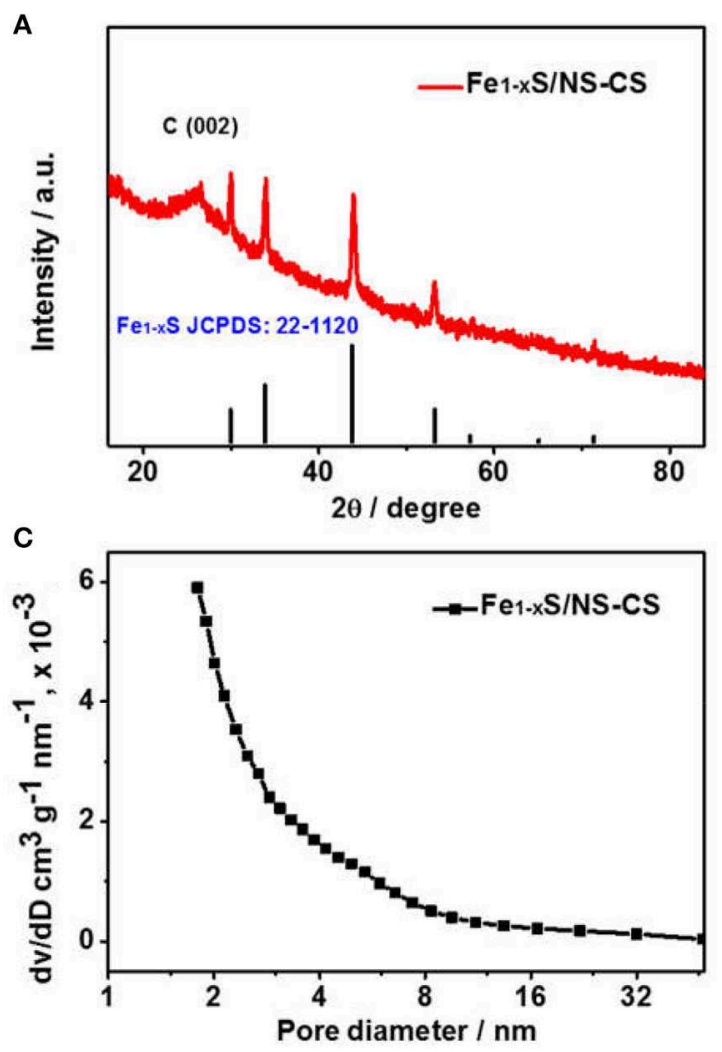

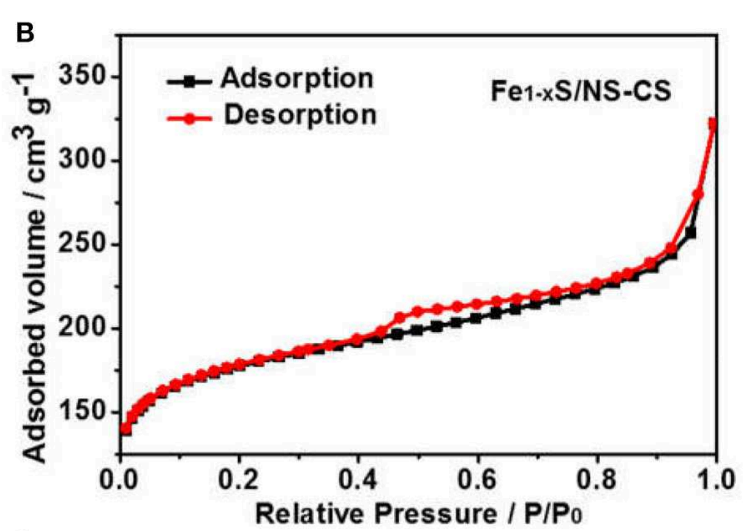

D

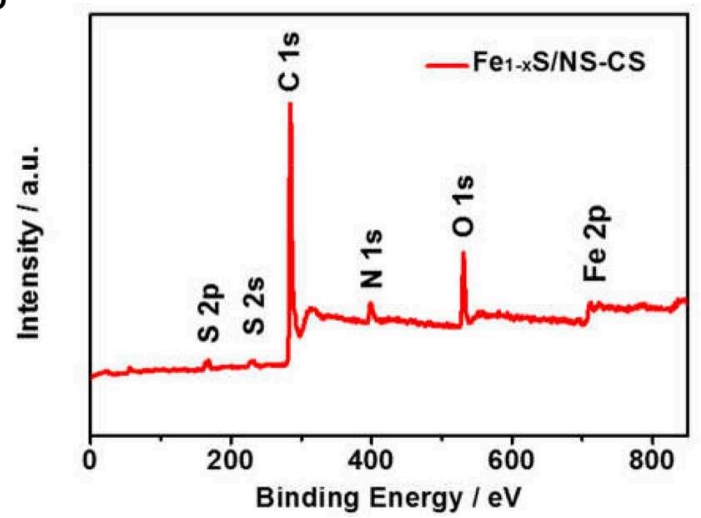

FIGURE 3 | (A) XRD patterns of $\mathrm{Fe}_{1-x} \mathrm{~S} / \mathrm{NS}-\mathrm{CS}$. (B) $\mathrm{N}_{2}$ sorption isotherms and (C) the corresponding pore size distribution (inset) of $\mathrm{Fe}_{1-x} \mathrm{~S} / \mathrm{NS}-\mathrm{CS}$. (D) XPS survey spectra of $\mathrm{Fe}_{1-x} \mathrm{~S} / \mathrm{NS}-\mathrm{CS}$.

pyrolysis and high-temperature vulcanization step. The accurate microstructures of $\mathrm{Fe}_{1-\mathrm{x}} \mathrm{S} / \mathrm{NS}$-CS are further investigated by HRTEM. Compared to the solid carbon spheres of Fe-NCPS, the $\mathrm{Fe}_{1-\mathrm{x}} \mathrm{S} / \mathrm{NS}-\mathrm{CS}$ sample not only shows the porous structure, but also displays a large number of $\mathrm{Fe}_{1-\mathrm{x}} \mathrm{S}$ nanoparticles $(\sim 18 \mathrm{~nm})$ embedded in the sphere (Figure 2d). A detailed examination of Figure $2 \mathrm{e}$ shows that the $\mathrm{Fe}_{1-\mathrm{X}} \mathrm{S}$ nanoparticles are well-encapsulated by graphitized carbon shells, where the lattice spacing of $0.340 \mathrm{~nm}$ corresponds to the (002) plane of graphitic carbon. Additionally, the interplanar lattice spacing of $0.260 \mathrm{~nm}$ observed in Figure $2 \mathbf{f}$ can be indexed to the (204) plane of crystalline $\mathrm{Fe}_{1-\mathrm{x}} \mathrm{S}$. Peculiarly, such a nanoparticleencapsulation geometric confinement structure can not only effectively suppress the oxidation, agglomeration, and dissolution of $\mathrm{Fe}_{1-\mathrm{x}} \mathrm{S}$ nanoparticles during the ORR catalysis process, but can also activate the interfacial contact between neighboring graphitic carbon layers and $\mathrm{Fe}_{1-\mathrm{x}} \mathrm{S}$ nanoparticles, thereby enhancing the ORR electrocatalytic activity and durability (Yang et al., 2010; Candelaria et al., 2012; Wu et al., 2012).

The specific surface area of $\mathrm{Fe}_{1-\mathrm{x}} \mathrm{S} / \mathrm{NS}-\mathrm{CS}$ is assessed by measuring the $\mathrm{N}_{2}$ sorption isotherm, and the corresponding pore size distribution is obtained by using the Barrett-Joyner-Halenda (BJH) method. It is noteworthy that the $\mathrm{Fe}_{1-\mathrm{x}} \mathrm{S} / \mathrm{NS}$-CS catalyst displays the type II adsorption isotherms with a typical type
H4 hysteresis loop (Figure 3B) as this indicates the coexistent of micropores and a mesoporous structure in the $\mathrm{Fe}_{1-\mathrm{x}} \mathrm{S} / \mathrm{NS}$ CS. In addition, such pore properties can also be confirmed from the corresponding pore size distribution. It can be seen from Figure $3 \mathrm{C}$ that the pore diameters in the $\mathrm{Fe}_{1-\mathrm{x}} \mathrm{S} / \mathrm{NS}-\mathrm{CS}$ are distributed in the range of 1.5 to $18 \mathrm{~nm}$. It is of note that the specific surface area, average pore size, and total pore volume of $\mathrm{Fe}_{1-\mathrm{x}} \mathrm{S} / \mathrm{NS}-\mathrm{CS}$ are calculated to be $628.7 \mathrm{~m}^{2} \mathrm{~g}^{-1}$, $6.67 \mathrm{~nm}$, and $0.50 \mathrm{~cm}^{3} \mathrm{~g}^{-1}$, respectively. The large surface area and abundant micropores and mesopores are expected to expose intensive catalytic active sites and facilitate the efficiency of ORRrelated ion diffusion, thus strengthening the ORR electrocatalytic activity (Liang et al., 2014).

To probe the elemental compositions and chemical state of $\mathrm{Fe}_{1-\mathrm{x}} \mathrm{S} / \mathrm{NS}$-CS, an X-ray photoelectron spectroscopy technic is employed. The full XPS survey spectra in Figure 3D indicates the presence of sulfur, carbon, nitrogen, oxygen, and iron species in the $\mathrm{Fe}_{1-\mathrm{x}} \mathrm{S} / \mathrm{NS}-\mathrm{CS}$ catalyst, and the corresponding surface contents of S, N, O, C, and Fe are 1.71 at \%, 5.00 at \%, 9.53 at \%, 82.73 at \%, and 1.04 at \%, respectively. The visibility of S $2 p$ and S $2 \mathrm{~s}$ signals observed in Figure 3D suggest that the sulfur species are successfully introduced into Fe/N-CS after the pyrolysis of thiourea. Figure 4A shows the high-resolution XPS spectrum, where the peaks observed at 285.3 and $286.7 \mathrm{eV}$ are assigned to 

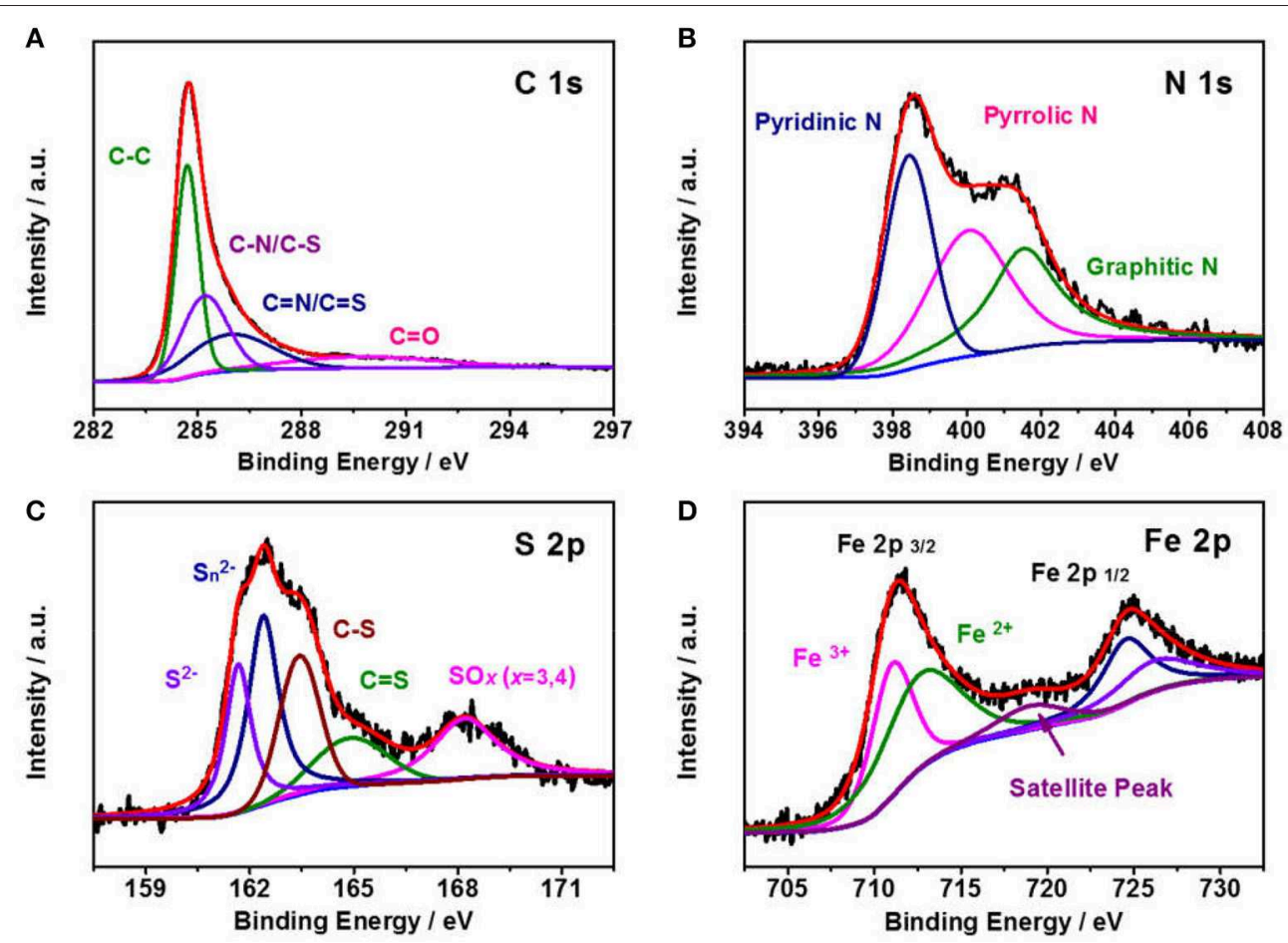

FIGURE 4 | High-resolution XPS spectra of (A) C 1s, (B) N 1s, (C) S 2p, and (D) Fe 2p for the $\mathrm{Fe}_{1-x} \mathrm{~S} / \mathrm{NS}-\mathrm{CS}$.

the $\mathrm{C}-\mathrm{N} / \mathrm{C}-\mathrm{S}$ and $\mathrm{C}=\mathrm{N} / \mathrm{C}=\mathrm{S}$ (Zhu et al., 2017), demonstrating the $\mathrm{N}$ and $\mathrm{S}$ atoms are successfully doped into carbon matrices. The high-resolution $\mathrm{N}$ 1s spectrum (Figure 4B) reveals the presence of three prominent bands at around 398.4, 400.5, and $401.8 \mathrm{eV}$, which corresponds to pyridinc $\mathrm{N}$, pyrrolic $\mathrm{N}$, and graphitic $\mathrm{N}$, respectively (Wang et al., 2017a). Figure 4C shows the highresolution S 2p spectrum of $\mathrm{Fe}_{1-\mathrm{x}} \mathrm{S} / \mathrm{NS}-\mathrm{CS}$, which can be fitted into five peaks, where the binding energies at 161.8 and $162.6 \mathrm{eV}$ are assigned to the $\mathrm{S}^{2-}$ and $\mathrm{S}_{\mathrm{n}}{ }^{2-}$ of $\mathrm{Fe}_{1-\mathrm{x}} \mathrm{S}$ (Bronold et al., 1997; Bukhtiyarova et al., 2000; Xiao et al., 2017a), while the peaks observed at 163.8 and $165.3 \mathrm{eV}$ belonged to the C-S and $\mathrm{C}=\mathrm{S}$ (Yang et al., 2011). In addition, the peak at the binding energy of $168.6 \mathrm{eV}$ in Figure 4C can be assigned to the oxidized sulfur species $\left(\mathrm{SO}_{\mathrm{X}}\right)$ due to the air contact (Wu et al., 2015). The high-resolution Fe 2 p spectrum of $\mathrm{Fe}_{1-\mathrm{x}} \mathrm{S} / \mathrm{NS}-\mathrm{CS}$ is displayed in Figure 4D, where the peaks centered at around 712 and $724 \mathrm{eV}$ can be assigned to the Fe $2 \mathrm{p}_{2 / 3}$ and $\mathrm{Fe} 2 \mathrm{p}_{2 / 1}$ in crystalline $\mathrm{Fe}_{1-\mathrm{x}} \mathrm{S}$ (Chen W. et al., 2011). Moreover, the appearance of the satellite peak located at $718.9 \mathrm{eV}$ indicated the co-existence of $\mathrm{Fe}^{2+}$ and $\mathrm{Fe}^{3+}$ in $\mathrm{Fe}_{1-\mathrm{x}} \mathrm{S} / \mathrm{NS}-\mathrm{CS}$ (Peng et al., 2013), further confirming the formation of $\mathrm{Fe}_{1-\mathrm{x}} \mathrm{S}$.

Motivated by the characteristic spherical nitrogen and sulfur co-doped graphitic carbon nanoskeleton incorporated with the $\mathrm{Fe}_{1-\mathrm{x}} \mathrm{S}$ nanoparticle-encapsulation structure, the ORR catalytic activities of $\mathrm{Fe}_{1-\mathrm{x}} \mathrm{S} / \mathrm{NS}$-CS were assessed in $\mathrm{O}_{2}$-saturated $0.1 \mathrm{M} \mathrm{KOH}$. Before that, the vulcanizing temperature was optimized (Figure S1). For comparison, N-CS, NS-CS, $\mathrm{Fe}_{3} \mathrm{O}_{4} / \mathrm{N}-$ CS (Figure S2), and commercial 20\% Pt/C catalysts were also investigated. Figure 5A shows the cyclic voltammograms (CVs) of all materials in $\mathrm{N}_{2}$ or $\mathrm{O}_{2}$-saturated $0.1 \mathrm{M} \mathrm{KOH}$, in which the cathodic peak potential of $\mathrm{Fe}_{1-\mathrm{x}} \mathrm{S} / \mathrm{NS}-\mathrm{CS}(0.828 \mathrm{~V}$, vs. RHE) is more positive compared to N-CS $(0.660 \mathrm{~V})$, NS-CS $(0.706 \mathrm{~V})$, and $\mathrm{Fe}_{3} \mathrm{O}_{4} / \mathrm{N}-\mathrm{CS}(0.759 \mathrm{~V})$, suggesting pronounced ORR catalytic activity of $\mathrm{Fe}_{1-\mathrm{x}} \mathrm{S} / \mathrm{NS}-\mathrm{CS}$ material. The corresponding linear sweep voltammetrys (LSVs) curves were recorded to further evaluate the excellent ORR catalytic performance of $\mathrm{Fe}_{1-\mathrm{x}} \mathrm{S} / \mathrm{NS}$ CS (Figure 5B). Remarkably, the onset potential $\left(\mathrm{E}_{0}\right)$ of the $\mathrm{Fe}_{1-\mathrm{x}} \mathrm{S} / \mathrm{NS}-\mathrm{CS}$ catalyst was $0.989 \mathrm{~V}$, which was more positive than that of $\mathrm{Pt} / \mathrm{C}$ catalyst $(0.973 \mathrm{~V})$ and much more positive than that of N-CS $(0.833 \mathrm{~V})$, NS-CS $(0.895 \mathrm{~V})$, and $\mathrm{Fe}_{3} \mathrm{O}_{4} / \mathrm{NS}-$ CS $(0.967 \mathrm{~V})$ (Table S1). Moreover, the $\mathrm{Fe}_{1-\mathrm{x}} \mathrm{S} / \mathrm{NS}-\mathrm{CS}$ held the most half-wave potential $\left(\mathrm{E}_{1 / 2}=0.840 \mathrm{~V}\right)$, which even exceeded the benchmarked $20 \% \mathrm{Pt} / \mathrm{C}(0.831 \mathrm{~V})$ and other Fe-based related electrocatalysts previously reported (Table S2). Figure 5C displays a Tafel slope of $79 \mathrm{mV} \mathrm{dec}^{-1}$ for the $\mathrm{Fe}_{1-\mathrm{x}} \mathrm{S} / \mathrm{NS}-\mathrm{CS}$ catalyst, which is very close to that of $\mathrm{Pt} / \mathrm{C}\left(67 \mathrm{mV} \mathrm{dec}^{-1}\right)$, highlighting the similar ORR kinetic processes of $\mathrm{Fe}_{1-\mathrm{x}} \mathrm{S} / \mathrm{NS}$ $\mathrm{CS}$ as commercial Pt/C. The excellent ORR electrocatalytic activity of $\mathrm{Fe}_{1-\mathrm{X}} \mathrm{S} / \mathrm{NS}$-CS is further confirmed by the much higher kinetic current density $J_{K}$, as shown in Figure 5D. The $J_{K}$ of $\mathrm{Fe}_{1-\mathrm{x}} \mathrm{S} / \mathrm{NS}-\mathrm{CS}\left(13.83 \mathrm{~mA} \mathrm{~cm}{ }^{-2}\right)$ was much higher than that of N-CS $\left(0.48 \mathrm{~mA} \mathrm{~cm}^{-2}\right)$, NS-CS $\left(0.94 \mathrm{~mA} \mathrm{~cm}^{-2}\right)$, and $\mathrm{Fe}_{3} \mathrm{O}_{4} / \mathrm{NS}-\mathrm{CS}\left(4.25 \mathrm{~mA} \mathrm{~cm}^{-2}\right)$ at the potential of $0.8 \mathrm{~V}$. To deeply elucidate the ORR pathway and kinetics, the LSVs of N-CS, NS-CS, $\mathrm{Fe}_{3} \mathrm{O}_{4} / \mathrm{N}-\mathrm{CS}, \mathrm{Fe}_{1-\mathrm{x}} \mathrm{S} / \mathrm{NS}-\mathrm{CS}$, and $20 \% \mathrm{Pt} / \mathrm{C}$ at different rotation rates $(625-2,500 \mathrm{rpm})$ were recorded (Figure $5 \mathrm{E}$ and 

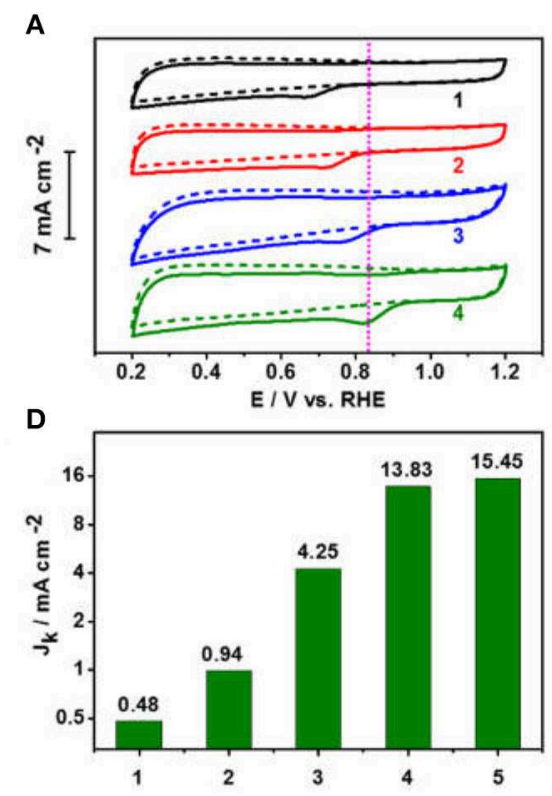

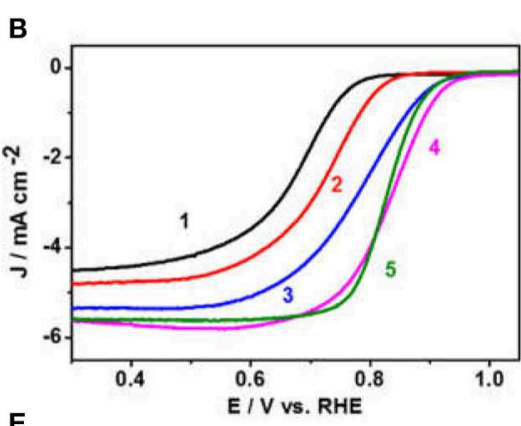

E

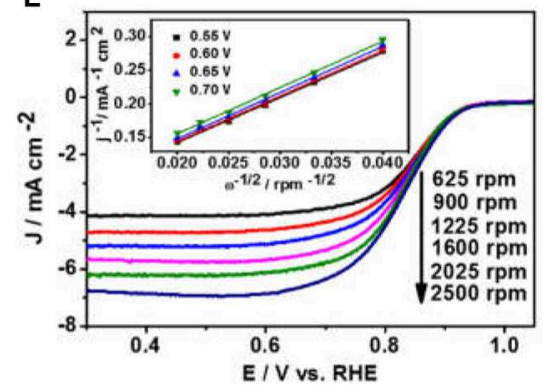

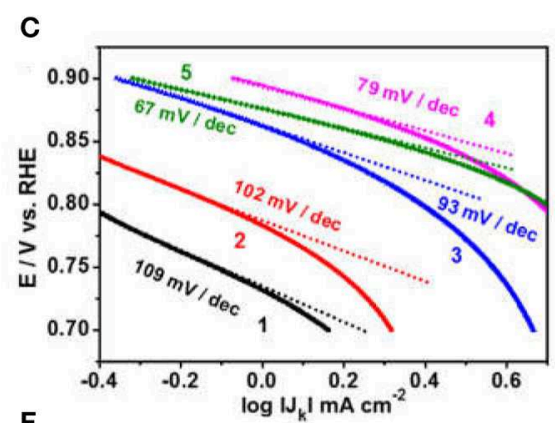

$F$

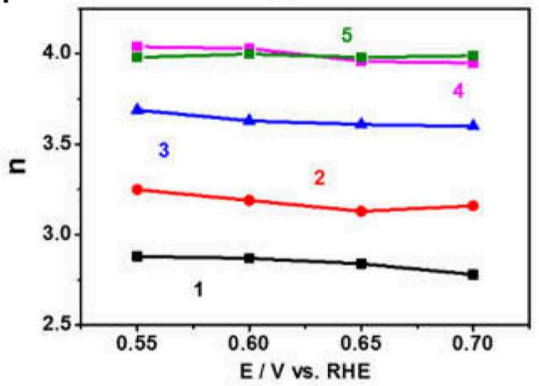

FIGURE 5 | (A) CVs in $\mathrm{N}_{2}$ or $\mathrm{O}_{2}$-saturated $0.1 \mathrm{M} \mathrm{KOH}$. (B) LSVs in $\mathrm{O}_{2}$-saturated $0.1 \mathrm{M} \mathrm{KOH}$. (C) Tafel plots and (D) the kinetic current density $\mathrm{J}_{K}$ at the potential of $0.8 \mathrm{~V}$. (E) LSVs of $\mathrm{Fe}_{1-x} \mathrm{~S} / \mathrm{NS}-\mathrm{CS}$ at different rotation rates (inset shows the corresponding K-L plots at $0.55-0.70 \mathrm{~V}$ ). (F) The electron transfer number. (1) N-CS, (2) NS-CS, (3) $\mathrm{Fe}_{3} \mathrm{O}_{4} / \mathrm{N}-\mathrm{CS}$, (4) $\mathrm{Fe}_{1-x} \mathrm{~S} / \mathrm{NS}-\mathrm{CS}$, and (5) $20 \% \mathrm{Pt} / \mathrm{C}$.

Figures S2-S5). Meanwhile, the corresponding K-L plots at different potentials $(0.55-0.7 \mathrm{~V})$ were also obtained, as shown in Figure 5E and Figures S3-S6. Unlike, the K-L plots of N-CS, NS-CS, $\mathrm{Fe}_{3} \mathrm{O}_{4} / \mathrm{N}-\mathrm{CS}$, the $\mathrm{Fe}_{1-\mathrm{x}} \mathrm{S} / \mathrm{NS}-\mathrm{CS}$ and $20 \% \mathrm{Pt} / \mathrm{C}$ exhibit good linearity with a similar slope, which is indicative of the firstorder ORR kinetics of $\mathrm{Fe}_{1-\mathrm{x}} \mathrm{S} / \mathrm{NS}-\mathrm{CS}$ and $20 \% \mathrm{Pt} / \mathrm{C}$. Figure $5 \mathrm{~F}$ displays the electron transfer number $(n)$ of N-CS, NS-CS, $\mathrm{Fe}_{3} \mathrm{O}_{4} / \mathrm{N}-\mathrm{CS}, \mathrm{Fe}_{1-\mathrm{x}} \mathrm{S} / \mathrm{NS}-\mathrm{CS}$, and $20 \% \mathrm{Pt} / \mathrm{C}$. The average values of $n$ at the potential range from 0.55 to $0.70 \mathrm{~V}$ for the N-CS, NS-CS, $\mathrm{Fe}_{3} \mathrm{O}_{4} / \mathrm{N}-\mathrm{CS}, \mathrm{Fe}_{1-\mathrm{x}} \mathrm{S} / \mathrm{NS}-\mathrm{CS}$, and $20 \% \mathrm{Pt} / \mathrm{C}$ were 2.84, $3.18,3.63,3.99$, and 3.98, respectively, revealing a dominant four-electron ORR catalytic pathway under the electrocatalyst of $\mathrm{Fe}_{1-\mathrm{x}} \mathrm{S} / \mathrm{NS}-\mathrm{CS}$.

According to above analysis, the $\mathrm{Fe}_{1-\mathrm{x}} \mathrm{S} / \mathrm{NS}$-CS sample displayed an efficient ORR activity and pathway, which can be ascribed to several factors. Firstly, the graphitic carbon matrixes contribute to excellent electrical conductivity and stability, thus leading to good electrochemical performances (Xia et al., 2016). Secondly, the $\mathrm{N}$ dopants, especially the graphitic $\mathrm{N}$ and pyridinic $\mathrm{N}$ dopant, modify the electroneutrality and fermi level of neighbor carbon atoms, thus facilitating the adsorption of $\mathrm{O}_{2}$ (Wang and Su, 2014). Thirdly, the introduction of S species into the carbon framework had an effect as well, since the S-dopants are beneficial for ORR electrocatalyst through the electron spin effect (Jeon et al., 2013; Wang et al., 2015; Wu et al., 2016). On the score, the improved catalytic activity that can be seen from the electrochemical activity is enhanced from N-CS to NS-CS (Figure 5B). Fourthly, the formed $\mathrm{Fe}_{1-\mathrm{x}} \mathrm{S}$ catalytic active substance and the possible synergetic interaction between $\mathrm{Fe}_{1-\mathrm{x}} \mathrm{S}$ nanoparticles and the protective $\mathrm{N}$ and $\mathrm{S}$ co-doped graphitic carbon layer would also contribute to the enhanced activity. In this case, the $\mathrm{Fe}_{1-\mathrm{x}} \mathrm{S} / \mathrm{NS}-\mathrm{CS}$ would hold the most half-wave potential $\left(\mathrm{E}_{1 / 2}=0.840 \mathrm{~V}\right)$, which is more positive than that of NS-CS and $\mathrm{Fe}_{3} \mathrm{O}_{4} / \mathrm{N}-\mathrm{CS}$ (Figure 5B). The important role of $\mathrm{Fe}_{1-\mathrm{x}} \mathrm{S}$ species in improving the ORR electrocatalytic performance has been clearly established. Finally, the large surface area and abundant porous carbon architectures are expected to expose intensive catalytic active sites and facilitate the mass transport efficiency (Liang et al., 2014). Summarily, the efficient ORR activity and pathway of $\mathrm{Fe}_{1-\mathrm{x}} \mathrm{S} / \mathrm{NS}-\mathrm{CS}$ are mainly attributed to the moderate $\mathrm{N}$ and $\mathrm{S}$ co-doping, the graphitic carbon nanoskeletons with large surface areas and abundant porous architectures, the formed $\mathrm{Fe}_{1-\mathrm{x}} \mathrm{S}$ catalytic active substance, and the possible synergetic interaction between $\mathrm{Fe}_{1-\mathrm{x}} \mathrm{S}$ nanoparticles and the protective $\mathrm{N}$ and $\mathrm{S}$ co-doped graphitic carbon layer.

For application, the outstanding methanol tolerance and stability are also necessary for an ORR electrocatalyst. The methanol resistance effect of $\mathrm{Fe}_{1-\mathrm{x}} \mathrm{S} / \mathrm{NS}-\mathrm{CS}$ was firstly evaluated by cycling the $\mathrm{Fe}_{1-\mathrm{x}} \mathrm{S} / \mathrm{NS}-\mathrm{CS}$ catalyst from 0.2 to $1.2 \mathrm{~V}$ in $\mathrm{O}_{2}$ saturated $0.1 \mathrm{M} \mathrm{KOH}$ with $2 \mathrm{M}$ methanol (Figure 6A), while the $20 \% \mathrm{Pt} / \mathrm{C}$ was also benchmarked (Figure S7). Impressively, the $\mathrm{CV}$ curve of $\mathrm{Fe}_{1-\mathrm{x}} \mathrm{S} / \mathrm{NS}-\mathrm{CS}$ has no obvious change in the presence of $2 \mathrm{M}$ methanol. However, for the $20 \% \mathrm{Pt} / \mathrm{C}$ catalysts, a distinct methanol oxidation peak appeared. Additionally, the effect of the methanol crossover for the $\mathrm{Fe}_{1-\mathrm{x}} \mathrm{S} / \mathrm{NS}-\mathrm{CS}$ and $20 \% \mathrm{Pt} / \mathrm{C}$ were also evaluated by the chronoamperometric response. As displayed in Figure 6B, there is no noticeable current attenuation for $\mathrm{Fe}_{1-\mathrm{x}} \mathrm{S} / \mathrm{NS}$-CS after injecting $\mathrm{CH}_{3} \mathrm{OH}$ as compared to $20 \% \mathrm{Pt} / \mathrm{C}$, demonstrating that the developed 

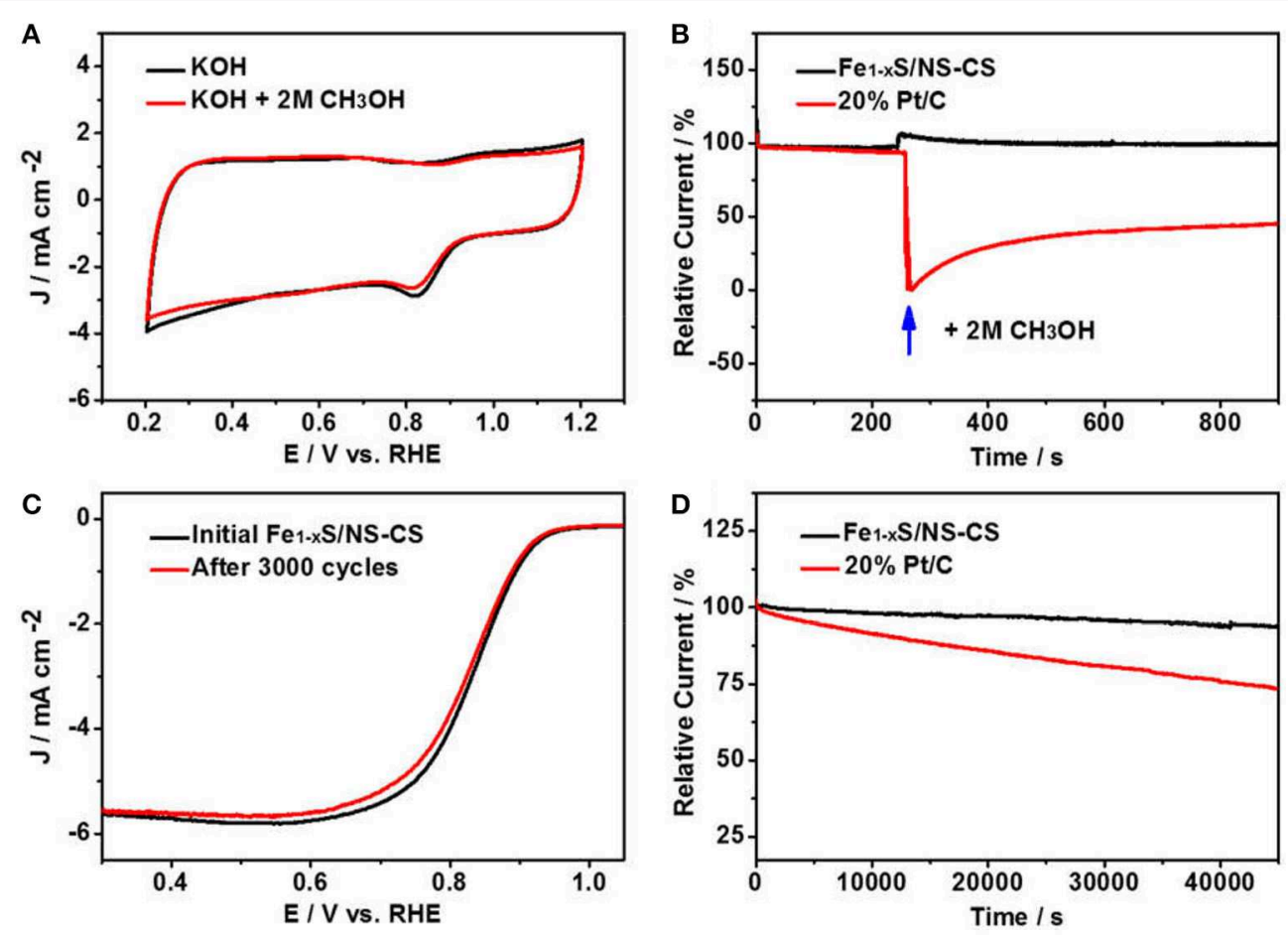

FIGURE 6 | (A) CVs of $\mathrm{Fe}_{1-x} \mathrm{~S} / \mathrm{NS}$-CS in $\mathrm{O}_{2}$-saturated $0.1 \mathrm{M} \mathrm{KOH}$ or in the presence of $2 \mathrm{M}$ methanol $\mathrm{O}_{2}$-saturated $0.1 \mathrm{M} \mathrm{KOH}$. (B) Chronoamperometric responses of $\mathrm{Fe}_{1-x} \mathrm{~S} / \mathrm{NS}-\mathrm{CS}$ and $20 \% \mathrm{Pt} / \mathrm{C}$ in $\mathrm{O}_{2}$-saturated $0.1 \mathrm{M} \mathrm{KOH}$ with an injection of $2 \mathrm{M}$ methanol. (C) $\mathrm{LSVS}$ of $\mathrm{Fe}_{1-x} \mathrm{~S} / \mathrm{NS}$-CS before and after 3,000 potential cycles. (D) Chronoamperometric responses of $\mathrm{Fe}_{1-x} \mathrm{~S} / \mathrm{NS}-\mathrm{CS}$ and $20 \% \mathrm{Pt} / \mathrm{C}$ at $0.6 \mathrm{~V}$ over $40,000 \mathrm{~s}$ (Relative Current = Measured Current/Initial Current).

$\mathrm{Fe}_{1-\mathrm{x}} \mathrm{S} / \mathrm{NS}-\mathrm{CS}$ material possesses excellent tolerance to methanol crossover. Figures 6C,D exhibit the results of several stability performance tests for the $\mathrm{Fe}_{1-\mathrm{x}} \mathrm{S} / \mathrm{NS}-\mathrm{CS}$ and Pt/C. Remarkably, the LSV curve of $\mathrm{Fe}_{1-\mathrm{x}} \mathrm{S} / \mathrm{NS}$-CS displays a negligible catalytic activity loss after 3,000 potential cycles (Figure S8). Moreover, the current loss for the $\mathrm{Fe}_{1-\mathrm{x}} \mathrm{S} / \mathrm{NS}$-CS catalyst was only about $6.4 \%$ after continuous operation for $45,000 \mathrm{~s}$, whereas $20 \%$ $\mathrm{Pt} / \mathrm{C}$ displayed a more rapid current loss. The above results convincingly showed that the $\mathrm{Fe}_{1-\mathrm{x}} \mathrm{S} / \mathrm{NS}$-CS not only holds an outstanding ORR catalytic performance but also possesses strong methanol tolerance and excellent ORR catalytic stability.

In summary, an excellent ORR catalyst, in which iron sulfide $\left(\mathrm{Fe}_{1-\mathrm{x}} \mathrm{S}\right)$ nanoparticles were embedded into a nitrogen and sulfur co-doped carbon sphere ( $\left.\mathrm{Fe}_{1-\mathrm{x}} \mathrm{S} / \mathrm{NS}-\mathrm{CS}\right)$, has been successfully explored through a simple and fast polymerization between MMA and AFC as well as a subsequent high-temperature vulcanization process. Compared to the commercial $\mathrm{Pt} / \mathrm{C}$ catalyst, the resulting $\mathrm{Fe}_{1-\mathrm{X}} \mathrm{S} / \mathrm{NS}$-CS demonstrated a superior ORR catalytic performance and methanol tolerance together with much better stability. Therein, the moderate $\mathrm{N}$ and $\mathrm{S}$ co-doping, the graphitic carbon nanoskeletons with large surface areas and abundant porous architectures, formed $\mathrm{Fe}_{1-\mathrm{x}} \mathrm{S}$ catalytic active substance, and the possible synergetic interaction between $\mathrm{Fe}_{1-\mathrm{x}} \mathrm{S}$ nanoparticles and the protective $\mathrm{N}$ and $\mathrm{S}$ codoped graphitic carbon layer further improve the outstanding electrocatalytic properties of $\mathrm{Fe}_{1-\mathrm{x}} \mathrm{S} / \mathrm{NS}-\mathrm{CS}$. In consideration of the simple and fast synthetic preparation, the strategy proposed here can potentially be employed for the synthesis of other nonnoble metal-based catalysts in large-scale industrial production.

\section{DATA AVAILABILITY STATEMENT}

All datasets generated for this study are included in the article/Supplementary Material.

\section{AUTHOR CONTRIBUTIONS}

All authors contributed to the writing of the manuscript and have given approval to the final version of the manuscript.

\section{FUNDING}

This research was supported by the Scientific Research Foundation of Wuhan Institute of Technology of China (Grant No. K201942). The National Key Research and Development Program of China (Grant No. 2018YFF0215002) and the Research Foundation of Education Bureau of Hunan Province of China (Grant No. 18B347) were also acknowledged. Furthermore, we also acknowledge the support of the Analytical and Testing Center of the Huazhong University of Science and Technology for XRD, SEM, and XPS measurements. 


\section{SUPPLEMENTARY MATERIAL}

The Supplementary Material for this article can be found online at: https://www.frontiersin.org/articles/10.3389/fchem. 2019.00855/full\#supplementary-material

\section{REFERENCES}

Bronold, M., Kubala, S., Pettenkofer, C., and Jaegermann, W. (1997). Thin pyrite $\left(\mathrm{FeS}_{2}\right)$ films by molecular beam deposition. Thin Solid Films 304, 178-182. doi: 10.1016/S0040-6090(97)00121-1

Bukhtiyarova, G. A., Bukhtiyarov, V. I., Sakaeva, N. S., Kaichev, V. V., and Zolotovskii, B. P. (2000). XPS study of the silica-supported Fe-containing catalysts for deep or partial H2S oxidation. J. Mol. Catal. A Chem. 158, 251-255. doi: 10.1016/S1381-1169(00)00085-6

Candelaria, S. L., Shao, Y., Zhou, W., Li, X., Xiao, J., Zhang, J.-G., et al. (2012). Nanostructured carbon for energy storage and conversion. Nano Energy 1, 195-220. doi: 10.1016/j.nanoen.2011.11.006

Chen, W., Li, S., Chen, C., and Yan, L. (2011). Self-assembly and embedding of nanoparticles by in situ reduced graphene for preparation of a 3D graphene/nanoparticle aerogel. Adv. Mater. 23, 5679-5683. doi: 10.1002/adma.201102838

Chen, Z., Higgins, D., Yu, A., Zhang, L., and Zhang, J. (2011). A review on non-precious metal electrocatalysts for PEM fuel cells. Energy Environ. Sci. 4, 3167-3192. doi: 10.1039/c0ee00558d

Dai, L., Xue, Y., Qu, L., Choi, H.-J., and Baek, J.-B. (2015). Metal-free catalysts for oxygen reduction reaction. Chem. Rev. 115, 4823-4892. doi: 10.1021/cr5003563

Greeley, J., Stephens, I., Bondarenko, A., Johansson, T. P., Hansen, H. A., Jaramillo, T., et al. (2009). Alloys of platinum and early transition metals as oxygen reduction electrocatalysts. Nat. Chem. 1, 552-556. doi: 10.1038/nchem.367

Guo, X., Qian, C., Shi, R., Zhang, W., Xu, F., Qian, S., et al. (2019). Biomorphic Co-N-C/CoOx composite derived from natural chloroplasts as efficient electrocatalyst for oxygen reduction reaction. Small 15:1804855. doi: 10.1002/smll.201804855

Jaouen, F., Proietti, E., Lefèvre, M., Chenitz, R., Dodelet, J.-P., Wu, G., et al. (2011). Recent advances in non-precious metal catalysis for oxygen-reduction reaction in polymer electrolyte fuel cells. Energy Environ. Sci. 4, 114-130. doi: 10.1039/C0EE00011F

Jeon, I., Zhang, S., Zhang, L., Choi, H., Seo, J., Xia, Z., et al. (2013). Edge-selectively sulfurized graphene nanoplatelets as efficient metal-free electrocatalysts for oxygen reduction reaction: the electron spin effect. Adv. Mater. 25, 6138-6145. doi: 10.1002/adma.201302753

Jin, H., Zhou, H., Li, W., Wang, Z., Yang, J., Xiong, Y., et al. (2018). In situ derived $\mathrm{Fe} / \mathrm{N} / \mathrm{S}$-codoped carbon nanotubes from ZIF-8 crystals as efficient electrocatalysts for oxygen reduction reaction and zinc-air batteries. J. Mater. Chem. A 6, 20093-20099. doi: 10.1039/C8TA07849A

Kim, B. J., Lee, D. U., Wu, J., Higgins, D., Yu, A., and Chen, Z. (2013). Ironand nitrogen-functionalized graphene nanosheet and nanoshell composites as a highly active electrocatalyst for oxygen reduction reaction. J. Phys. Chem. C 117, 26501-26508. doi: 10.1021/jp410014a

Liang, H.W., Zhuang, X., Brüller, S., Feng, X., and Müllen, K. (2014). Hierarchically porous carbons with optimized nitrogen doping as highly active electrocatalysts for oxygen reduction. Nat. Commun. 5:4973. doi: 10.1038/ncomms5973

Liu, Q., Du, L., Fu, G., Cui, Z., Li, Y., Dang, D., et al. (2019). Structurally ordered $\mathrm{Fe}_{3} \mathrm{Pt}$ nanoparticles on robust nitride support as a high performance catalyst for the oxygen reduction reaction. Adv. Energy Mater. 9:1803040. doi: 10.1002/aenm.201803040

Ma, F., Zhao, H., Sun, L., Li, Q., Huo, L., Xia, T., et al. (2012). A facile route for nitrogen-doped hollow graphitic carbon spheres with superior performance in supercapacitors. J. Mater. Chem. 22, 13464-13468. doi: 10.1039/c2jm3 2960c

Peng, H., Mo, Z., Liao, S., Liang, H., Yang, L., Luo, F., et al. (2013). High performance $\mathrm{Fe}$-and $\mathrm{N}$-doped carbon catalyst with graphene structure for oxygen reduction. Sci. Rep. 3:1765. doi: 10.1038/srep01765
Supplementary data associated with this article-physical characterization and electrochemical measurements details, XRD patterns, and electrochemical measurement data-are available in the Supplementary Material.

Wang, D.-W., and Su, D. (2014). Heterogeneous nanocarbon materials for oxygen reduction reaction. Energy Environ. Sci. 7, 576-591. doi: 10.1039/c3ee43463j

Wang, H., Wang, W., Asif, M., Yu, Y., Wang, Z., Wang, J., et al. (2017a). Cobalt ion-coordinated self-assembly synthesis of nitrogen-doped ordered mesoporous carbon nanosheets for efficiently catalyzing oxygen reduction. Nanoscale 9, 15534-15541. doi: 10.1039/C7NR05208A

Wang, H., Wang, W., Gui, M., Asif, M., Wang, Z., Yu, Y., et al. (2017b). Uniform $\mathrm{Fe}_{3} \mathrm{O}_{4} /$ nitrogen-doped mesoporous carbon spheres derived from ferric citratebonded melamine resin as an efficient synergistic catalyst for oxygen reduction. ACS Appl. Mater. Interfaces 9, 335-344. doi: 10.1021/acsami.6b11608

Wang, H., Wang, W., Zaman, S., Yu, Y., Wu, Z., Liu, H., et al. (2018). Dicyandiamide and iron-tannin framework derived nitrogen-doped carbon nanosheets with encapsulated iron carbide nanoparticles as advanced $\mathrm{pH}$ universal oxygen reduction catalysts. J. Colloid Interface Sci. 530, 196-201. doi: 10.1016/j.jcis.2018.06.085

Wang, S., Jang, H., Wang, J., Wu, Z., Liu, X., and Cho, J. (2019a). Cobalt-tanninframework-derived amorphous $\mathrm{Co}-\mathrm{P} / \mathrm{Co}-\mathrm{N}-\mathrm{C}$ on $\mathrm{N}, \mathrm{P}$ co-doped porous carbon with abundant active moieties for efficient oxygen reactions and water splitting. ChemSusChem 12, 830-838. doi: 10.1002/cssc.201802909

Wang, S., Nam, G., Li, P., Jang, H., Wang, J., Kim, M. G., et al. (2018). Highly active bifunctional oxygen electrocatalysts derived from nickel-or cobalt-phytic acid xerogel for zinc-air batteries. Nanoscale 10, 15834-15841. doi: 10.1039/C8NR04733B

Wang, S., Yan, X., Wu, K. H., Chen, X., Feng, J. M., Lu, P., et al. (2019b). A hierarchical porous Fe-N impregnated carbon-graphene hybrid for high-performance oxygen reduction reaction. Carbon 144, 798-804. doi: 10.1016/j.carbon.2018.12.066

Wang, Y., Lai, Y., Song, L., Zhou, Z., Liu, J., Wang, Q., et al. (2015). Sdoping of an $\mathrm{Fe} / \mathrm{N} / \mathrm{C}$ ORR catalyst for polymer electrolyte membrane fuel cells with high power density. Angew. Chem. Int. Ed. 54, 9907-9910. doi: 10.1002/anie.201503159

Wu, R., Wang, D. P., Rui, X., Liu, B., Zhou, K., Law, A. W., et al. (2015). In-situ formation of hollow hybrids composed of cobalt sulfides embedded within porous carbon polyhedra/carbon nanotubes for high-performance lithium-ion batteries. Adv. Mater. 27, 3038-3044. doi: 10.1002/adma.2015 00783

Wu, Z., Liu, R., Wang, J., Zhu, J., Xiao, W., Xuan, C., et al. (2016). Nitrogen and sulfur co-doping of 3D hollow-structured carbon spheres as an efficient and stable metal free catalyst for the oxygen reduction reaction. Nanoscale 8, 19086-19092. doi: 10.1039/C6NR06817K

Wu, Z.-S., Yang, S., Sun, Y., Parvez, K., Feng, X., and Mullen, K. (2012). 3D nitrogen-doped graphene aerogel-supported $\mathrm{Fe}_{3} \mathrm{O}_{4}$ nanoparticles as efficient electrocatalysts for the oxygen reduction reaction. J. Am. Chem. Soc. 134, 9082-9085. doi: 10.1021/ja3030565

Xia, B. Y., Yan, Y., Li, N., Wu, H. B., Lou, X. W. D., and Wang, X. (2016). A metalorganic framework-derived bifunctional oxygen electrocatalyst. Nat. Energy 1:15006. doi: 10.1007/978-981-10-0218-2

Xiao, J., Xia, Y., Hu, C., Xi, J., and Wang, S. (2017a). Raisin bread-like iron sulfides/nitrogen and sulfur dual-doped mesoporous graphitic carbon spheres: a promising electrocatalyst for the oxygen reduction reaction in alkaline and acidic media. J. Mater. Chem. A 5, 11114-11123. doi: 10.1039/C7TA02096A

Xiao, J., Xu, Y., Xia, Y., Xi, J., and Wang, S. (2016). Ultra-small $\mathrm{Fe}_{2} \mathrm{~N}$ nanocrystals embedded into mesoporous nitrogen-doped graphitic carbon spheres as a highly active, stable, and methanol-tolerant electrocatalyst for the oxygen reduction reaction. Nano Energy 24, 121-129. doi: 10.1016/j.nanoen.2016.04.026

Xiao, J., Zhao, C., Hu, C., Xi, J., and Wang, S. (2017b). Pudding-typed cobalt sulfides/nitrogen and sulfur dual-doped hollow carbon spheres as a highly 
efficient and stable oxygen reduction electrocatalyst. J. Power Sources 348, 183-192. doi: 10.1016/j.jpowsour.2017.03.011

Yang, S., Feng, X., Ivanovici, S., and Müllen, K. (2010). Fabrication of graphene-encapsulated oxide nanoparticles: towards high-performance anode materials for lithium storage. Angew. Chem. 122, 8586-8589. doi: 10.1002/ange.201003485

Yang, Z., Yao, Z., Li, G., Fang, G., Nie, H., Liu, Z., et al. (2011). Sulfur-doped graphene as an efficient metal-free cathode catalyst for oxygen reduction. ACS Nano 6, 205-211. doi: 10.1021/nn203393d

Yuan, B., Nam, G., Li, P., Wang, S., Liu, X., and Cho, J. (2019). Fe-NC combined with $\mathrm{Fe} 100-\mathrm{xy}-\mathrm{zPxOyNz}$ porous hollow spheres on a phosphoric acid grouprich N-doped carbon as an electrocatalyst for zinc-air battery. Appl. Surf. Sci. 481, 498-504. doi: 10.1016/j.apsusc.2019.03.137

Zhang, C. L., Lu, B. R., Cao, F. H., Wu, Z. Y., Zhang, W., Cong, H. P., et al. (2019). Electrospun metal-organic framework nanoparticle fibers and their derived electrocatalysts for oxygen reduction reaction. Nano Energy 55, 226-233. doi: 10.1016/j.nanoen.2018.10.029
Zhu, C., Aoki, Y., and Habazaki, H. (2017). $\mathrm{Co}_{9} \mathrm{~S}_{8}$ Nanoparticles incorporated in hierarchically porous $3 \mathrm{D}$ few-layer graphene-like carbon with S, N-doping as superior electrocatalyst for oxygen reduction reaction. Part. Part. Syst. Charact. 34:1700296. doi: 10.1002/ppsc.2017 00296

Conflict of Interest: The authors declare that the research was conducted in the absence of any commercial or financial relationships that could be construed as a potential conflict of interest.

Copyright (c) 2019 Wang, Qiu, Wang, Jiang and Liu. This is an open-access article distributed under the terms of the Creative Commons Attribution License (CC BY). The use, distribution or reproduction in other forums is permitted, provided the original author(s) and the copyright owner(s) are credited and that the original publication in this journal is cited, in accordance with accepted academic practice. No use, distribution or reproduction is permitted which does not comply with these terms. 